\title{
The Growth of Leading Regional Newspapers
}

\author{
Tom Björkroth \& Mikko Grönlund ${ }^{1}$
}

\begin{abstract}
Theoretical research has modelled the existence of so-called advertising-circulation spirals of newspapers. The present article examines the existence and shape of the growth functions of circulation for leading regional newspapers in Finland, and assesses their effects on their competitors. The article also provides results on the household coverage of the regionally leading newspapers. Our results enable us to draw conclusions concerning the level of convergence of the market shares of the larger newspapers, and the possibilities of the minority newspapers to survive. The findings relate directly to the assessment of competition in the market of newspaper publishing, as economic analysis has already shown that difference in size between the two largest firms may define the scope for dominance. Consequently, the results may have implications for assessments of the relevant market and the state of the competition, and claims concerning dominance in newspaper markets.
\end{abstract}

Keywords: newspapers, circulation, competition, market concentration, household coverage, regional markets

\section{Introduction}

The observation regarding the tendency towards increasing market concentration in newspaper publishing is by no means a new one. For example Picard (1988) examined the concentration in the U.S. newspaper industry using daily papers in local markets and found evidence of high concentration. Increasing market concentration has been argued to result in one-newspaper cities. This phenomenon, which has raised concerns from both competition and pluralism points of view, has been argued to result from scale economies in newspaper publishing and from the so-called advertising-circulation spiral. In this article, we will focus on the latter, where the causation can run directly from advertising to circulation, or via quality enhancements made possible by increasing advertising revenues. A formalized model of the theory of advertising and a quality-driven spiral has been presented by Gabszewicz, Garella and Sonnac (2007). They found that the pattern of market share growth of a leading newspaper may be convex or alternatively strictly convex, depending on the degree of ad-lovership of the audience, the number of advertisers, and the original size of the paper.

For competitors to a continuously growing leading newspaper, the situation means either a vicious downward spiral that results in an inevitable exit, or alternatively, that 
they are left a small fringe of the market, which may or may not be enough for them to survive on. In the long run, such a development will have implications for the competition in the market for newspaper publishing. The growth of one newspaper may increase its market power in both circulation and advertising, provided that it is not constrained by other media. The relative size is important, because the difference in size between the two largest firms in the market has been shown to indicate dominance. ${ }^{2}$ Moreover, the unfettered growth of market shares in newspaper publishing, in combination with increasing cross-ownership in the media, may also affect the degree of pluralism of opinions in the media. ${ }^{3}$ Consequently, the assessment of media mergers addresses a number of concerns. A possible counterweight to these concerns is that competition may over time develop from being a "within the region" phenomenon to competition "between the regional papers".

We do not at this stage strive to make a distinction between the forces at work behind these concentration spirals, but rather focus on the empirical identification of these spirals. The aim of the present article is to estimate the parameters in the growth functions describing the share of circulation for some regionally dominant ${ }^{4}$ newspapers. By doing this, we may draw conclusions concerning the possibilities of the smaller regional newspapers to survive. Our data cover both bilingual and predominantly monolingual regions, which enables us to compare the results between these regions. Hence, our conclusions on the prospects of survival for the smaller newspapers extend to the survival of the minority language newspapers as well. The survival of non-leading newspapers may be considered essential to the competition prevailing in the market, although increasing concentration per se does not rule out the existence of competitive pressure. In addition, the aim of the present article is to show that growth in the share of circulation does not necessarily imply an increase in household coverage. We will estimate the growth functions of the household coverage of a sample of the largest regional newspapers. Consequently, we can infer whether the leading regional newspapers grow in a declining market. Björkroth and Grönlund (2011) studied how competition and the related, relevant institutional framework had developed in the regionally very concentrated Finnish market for newspaper publishing between 1997 and 2008. The main conclusion was that newspapers had experienced an increasing competitive pressure from other media, with some temporary relief. At the same time, competition between newspapers was increasing rather than decreasing, but these results also show some temporal variation.

The structure of the article is as follows. The next section will briefly elaborate the model of Gabszewicz et al. (2007) to the extent it is relevant to the present article. Section 3 describes the approach and methods used in the empirical part of the article. Section 4 gives an overview of the markets under scrutiny. The data, estimation and the main results are presented in Section 5, and Section 6 concludes the article.

\section{On the Theory of the Circulation Spiral and the Method Used}

\section{A Brief Description of the Theory and its Implications}

Gabszewicz et al. (2007) noted that the circulation spiral has received two interpretations, of which the first is the advertising-driven spiral and the second is the qualitydriven spiral. In the advertising-driven spiral, readers are thought of as being ad-lovers. Otherwise this circle proceeds along the lines of Furhoff's idea, but the smaller news- 
paper is caught in a fateful downward spin with loss of appeal to advertisers followed by reduction in readership and so on (cf. Gustafsson, 1978, 1).

Gabszewicz et al. (2007) have formally modelled both the spirals mentioned and thus determined the growth paths of circulation of two newspapers $(i=1.2)$ that face an ad-loving readership, which adds to unity $\left(\lambda_{1}+\lambda_{2}=1\right)$. They let a parameter $s(s>0)$ describe the degree of ad-lover ship and $A$ denotes the total number of advertisers. The circulation of the larger newspaper 1 at time $t$ is determined by:

$$
n_{1}(t)=\frac{s \lambda_{2} A\left(2 \lambda_{1}-1\right)}{s \lambda_{2} A-1}\left(s \lambda_{2} A\right)^{t}+\frac{\lambda_{1}-s \lambda_{2} A}{1-2 s \lambda_{2} A}
$$

The idea is that the circulation spiral is positive for $\beta={ }_{S \lambda} \lambda_{2} A<1$, but with $\beta>1$ there is no possibility for paper 2 to retain a positive market share, at least in the long run, as is then strictly positive in $t^{5}$

The alternative explanation to the circulation spiral is that it is induced or actually strengthened by quality improvements. An increase in the audience size attracts more advertising revenue, which enables quality-improving investments, which again make the newspaper more attractive, and so on. This interpretation of a quality-driven spiral suggests that a newspaper that is gaining market shares at the expense of its rivals has succeeded in relative improvements in scope, editorial control, printing and other technical qualities as well as speed of distribution, for example. ${ }^{6}$

\section{Approach and Method}

The growth in the market share, or the diffusion pattern of a newspaper, can be described by a number of different models. For example, the logarithmic autoregressive trend model can capture both the idea that $\beta<1$ and that $\beta>1$. However, estimating a logistic growth curve may give a more nuanced picture of the changing market shares. The logistic equation of growth of circulation (absolute or relative to total circulation, for example), $y_{t}$ can be formulated as a function of time $(t)$ as:

$$
y_{t}=\frac{1}{k+a b^{t}}, \text { where } b>0
$$

Equation (1) is non-linear in its parameters $k, a$, and $b$, but can be estimated using nonlinear least squares. With the logistic growth curve, we may identify markets where the diffusion pattern of growing newspapers is S-shaped, i.e. where $0<b<1$. It also captures the mirror image, i.e. the diffusion pattern of newspapers that are caught in a vicious advertising circulation spiral, for example. In that case we have $b>1 .^{7}$

It is also possible that the series describing a growing circulation will not exhibit an S-shape, but rather illustrate continuing and accelerating growth. This may occur if the series studied is relatively short and/or manages to capture only this transitory phase of circulation growth. In this case, the development can be described by a quadratic trend model:

$$
y_{t}=c_{1}+c_{2} t+c_{3} t^{2}
$$


The parameters $c_{2}$ and $c_{3}$ are both positive in case of strict growth of $y_{t}$ and negative in case of a strict decline in market share. The basic idea of the present paper can be illustrated as in Figure 1, although the standard logistic function will be slightly modified in the estimation stage.

Figure 1. Examples of Different Growth Functions

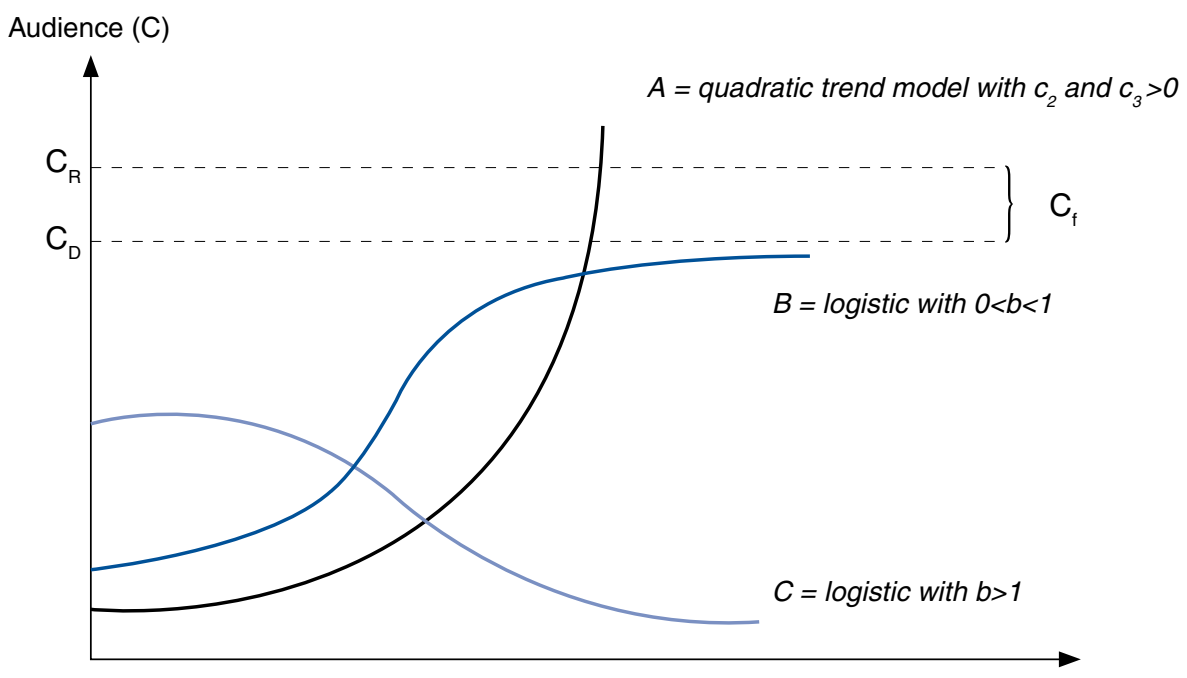

Time (t)

In the figure, $\mathrm{C}_{\mathrm{D}}$ depicts the market share that the dominant newspaper's market share approaches as time increases. The $\mathrm{C}_{\mathrm{F}}$ denotes the fringe for the smaller newspapers, i.e. the difference between the market size of the region $\left(\mathrm{C}_{\mathrm{R}}\right)$ and the share of the dominant firm. A similar level of convergence can be illustrated for declining newspapers or for decreasing household coverage of newspapers, for example.

\section{Newspapers and other Media - On the Role of the Potential Audience}

So far we have focused solely on the growing and declining newspapers' market shares, i.e. shares of total newspaper circulation within a certain geographical area. In doing this we have taken the view that the product market is rather narrowly defined to include only paid-for newspapers ${ }^{8}$. However, as we know regarding partly advertising financed media, both the audience and the advertisers have alternative channels at their disposal. Grönlund and Björkroth (2011) studied the implications of the substitutability between newspapers and other media for the inter-media competition and found evidence of simultaneously intensified intra-, but especially inter-media competition in the Finnish newspaper markets. ${ }^{9}$

With regard to this we should try to elaborate on the differences in conclusions that arise between relating the circulation growth to overall circulation of newspapers and setting the growth in circulation in relation to what seems to be the potential audience within a well-defined geographical area. 
Figure 2. Graphical Illustration of the Research Problem
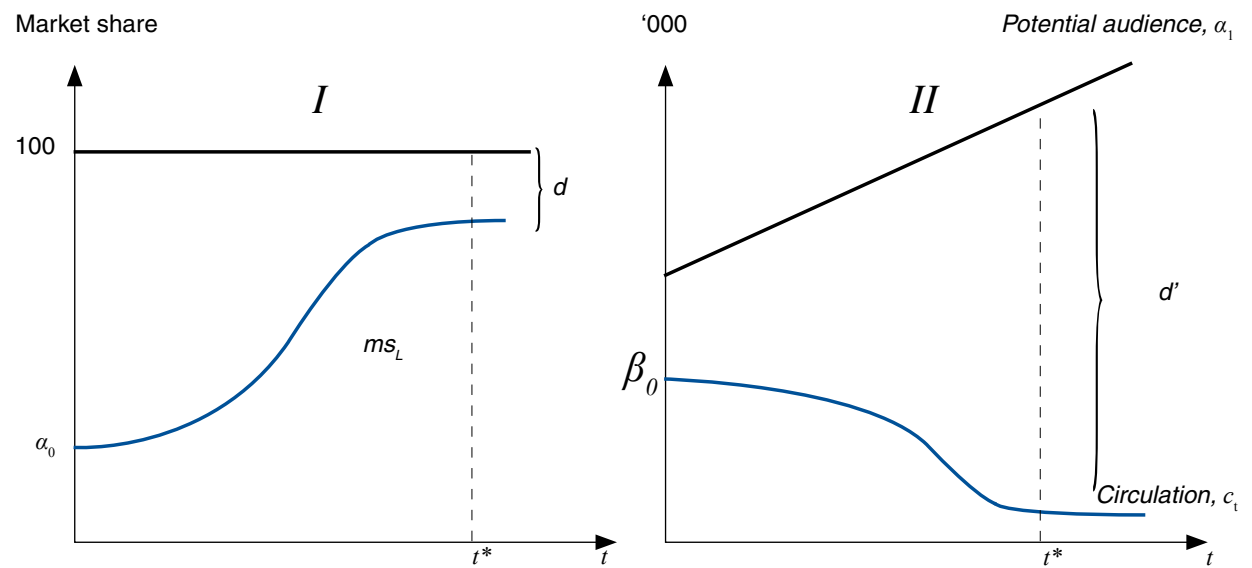

Figure 2 highlights more clearly our research problem at hand; if we look at a very narrowly defined market of newspapers, we may observe the market share of a leading newspaper to evolve like the curve $m s_{L}$ in panel $I$, indicating that at time $t^{*}$ the leading newspaper's market power can only be restricted by one or several firms operating in the fringe $d$. Consequently, it would be easy to arrive at a conclusion of single-firm dominance in the market for newspapers. But if we take a wider perspective and recognize the change in the media consumption patterns of the potential audience or consumers, we may for this same newspaper end up with a situation illustrated in panel II. Now the fringe or gap $d$, i.e. the difference between the actual circulation and what we could call the potential audience, illustrates the potential of competitive pressure from not only competing newspapers, but from other media as well. The gap $d$ ' can be interpreted as numbers, but once we know the media consumption habits in minutes per day, for example, it could be calculated in time devoted to the leading newspaper and to other media, respectively.

It is possible that the issue of dominance inferred from panel $I$ has to be reconsidered when it coincides with a situation such as in panel $I I$. In the end, the assessment depends on the substitutability between the different media both from the readers' and the advertisers' points of view. Before rejecting the hypothesis of market dominance, one has to take into account the possibility of cross-ownership across different media in the geographical market concerned. ${ }^{10}$ Moreover, one needs to rule out the possibility that a large part of the potential audience has not left the (wider) market altogether. ${ }^{11}$

\section{The Regional Markets}

\section{Brief Overall Market Description}

Finland is often cited as having a successful newspaper industry model that is built upon a structure of strong national and provincial papers, supplemented by smaller, more local papers (Picard \& Grönlund, 2003). The characteristics of the Finnish newspaper landscape include the strong subscription model, which was subsidized with a zero VAT rate until 2011, ${ }^{12}$ and the home delivery system, which is exceptional from an international 
perspective. Ninety per cent of newspaper sales are based on subscriptions and home delivery. The only exceptions are the two national tabloids (Ilta-Sanomat and Iltalehti), which are sold as single copies. For other newspapers, single copy sales are marginal (Grönlund \& Björkroth 2011, 31-32).

The efficient Finnish system of early-morning home delivery has traditionally meant that Finnish newspapers have been deeply interlocked with the local retail business. Advertisers need to reach specific audiences that are often defined by locations adjacent to stores they operate or geographic areas in which their products or services are distributed to retailers (Picard, 2002). The big retail stores have been important advertisers for the (local) Finnish newspapers, just as in other countries (e.g., Jyrkiäinen \& Savisaari 2003, 65). It is an important customer segment for all media, as one quarter (23 per cent) of total advertising spending in Finland comes from the retail business (TNS Media Intelligence 2012).

The per capita consumption of print media in Finland has long been one of the highest in the world, and newspaper reading continues to be a widespread activity among Finns. The strength of newspaper use in the country is often explained by political and socio-cultural factors in the Nordic countries. The strong position of print media is also reflected in the breakdown of the advertising expenditure by different media. In 2010, the share of print media was still clearly more than half $(58 \%)$ of the total media advertising.

Reading has decreased, but Finnish people still remain quite avid readers. In 1994, the share of newspaper reading of total media usage was 8.6 per cent and in 2009 it was still 7.1 per cent. In 2009, the average media usage was 7 hours and 30 minutes per day, and of that time 32 minutes were spent reading newspapers. Newspapers still have a very high level of readership in Finland, as almost eight out of ten of the population over 10 years of age read newspapers every day.

At the national level, the Finnish newspaper market does not seem very concentrated. The Herfindahl-Hirschman index for circulation $\left(\mathrm{HHI}_{\mathrm{C}}\right)$ is about 1000 , i.e. clearly lower than the corresponding index for advertising revenues $\left(\mathrm{HHI}_{\mathrm{A}}\right)$, which is about 1500 (Grönlund \& Björkroth, 2011). A national level perspective on newspaper markets overlooks many important nuances of competition, such as the regional character of newspaper markets in Finland. The Finnish press has a strong regional and local focus, although there is a handful of what might be classified as national newspapers. One indicator of the strength of the provincial press is that among the 20 biggest newspapers, measured by circulation, 14 are provincial (Björkroth \& Grönlund, 2011).

There are relatively large differences between the various regions of Finland ${ }^{13}$ concerning demographics (population growth and migration, number of households, age distribution) and economic features, such as the level and growth of GDP per capita or the structure of the economy (share of services to primary production). A summary of the key statistics is found in Table 1. These features affect the general market characteristics for newspaper publishing, such as the actual or potential subscribers and advertisers, size of the newspaper market/region and overall newspaper readership, for example.

Finland is known for being a relatively large but sparsely populated country, and many national industries are characterized by quite high concentration levels. The regional markets of newspaper publishing make no exception here. If we focus on ownership, the regional concentration levels in newspaper circulation and especially in newspaper advertising are extremely high. Figure 3 shows the combined regional 
market shares in newspaper circulation and advertising of the two largest owners, i.e. the traditional CR2 measure of concentration. ${ }^{14}$

Figure 3. Regional CR2 Figures (ownership) on Advertising and Circulation in the Market for Newspaper Publishing in 2008

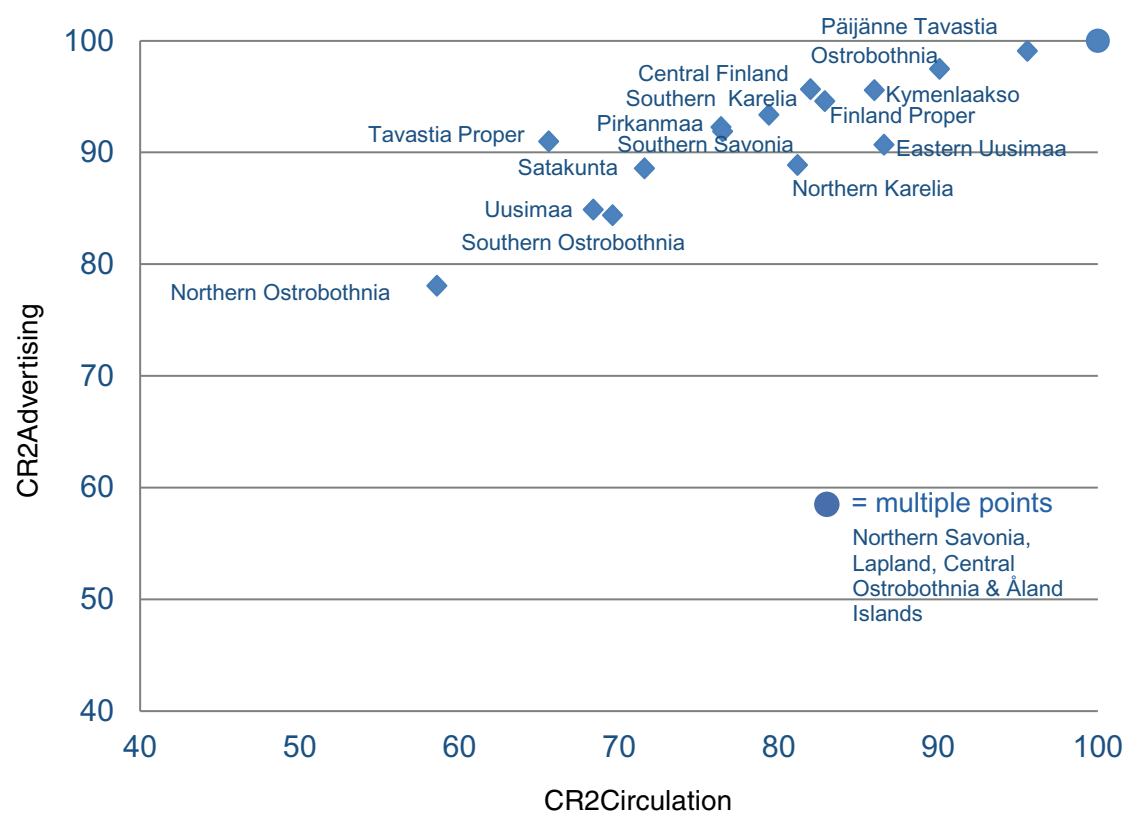

Source: Björkroth \& Grönlund, 2012.

From Figure 3 we see that the share of newspaper advertising of the two largest publishers is larger than their share of total circulation, i.e. the observations are above the 45 diagonal. The figure also reveals that the ownership concentration measured by CR2 is exceptionally high; exceeding 95 per cent in a number of regions in both newspaper circulation and newspaper advertising. These concentration levels further motivate a study on the dynamics of market share growth of the leading newspapers, and suggest that one could find a number of regional virtuous circulation spirals.

\section{Selection of Regions}

The choice of which regions to include in the study was made on the following criteria. The geographical market should be rather well defined, i.e. the share of newspapers "imported" from other regions should be quite low and the "exports" of the region's own newspaper should not be too large in relation to the "production" in the region. ${ }^{15}$ As our idea was to identify and determine the shape of virtuous circulation spirals, we can at this stage differentiate between the regions and concentrate the analysis on those regions where the leading newspaper has unanimously increased its market share. These eight regions are: Tavastia Proper, Pirkanmaa, Kymenlaakso, North Karelia, South Karelia, Southern Ostrobothnia, Lapland and Uusimaa. In addition to these regions, we will briefly focus on the development in the other two bilingual regions: Eastern Uusimaa and Ostrobothnia. 
Finnish and Swedish are the national languages of Finland, with equal status in the jurisdiction, although Finnish dominates in most parts of the country. "The other domestic language" is studied in compulsory education, and bilingualism is quite common in some parts of the country. In 2010, Swedish was the mother tongue of about 266,000 people in mainland Finland and of about 25,000 people on the Åland Islands, together representing about 5.4 per cent of the total population.

Eastern Uusimaa was a region in Finland, until it was merged with the region of Uusimaa on 1 January 2011. The surface area of the region was the smallest of the Finnish regions. There were 7 municipalities in Eastern Uusimaa and only two municipalities were unilingually Finnish. The region had two cities. The regional capital was Porvoo, with a population of 48,768 inhabitants. In 2010, Eastern Uusimaa had a population of 94,353 of whom 61.5 per cent spoke Finnish as their native language and 31.7 per cent spoke Swedish as their native language. The population of the region represents 1.8 per cent of the total population of Finland, and the population density is 34.9 inhabitants per $\mathrm{km}^{2}$.

Ostrobothnia is a region on the coast of the Kvarken. The population of the region represents 3.3 per cent of Finland's population, and the population density is 23.0 inhabitants per $\mathrm{km}^{2}$. There are 16 municipalities in Ostrobothnia. Six of them are cities and Vaasa, the regional centre, is clearly the largest city in the area $(59,587$ inhabitants). Three of the municipalities are traditionally unilingually Finnish, others have earlier been unilingually Swedish, as municipalities like Närpes, Korsnäs and Luoto, continue to be. Most of the other municipalities are presently bilingual, as the old coastal cities have historically always been. In the bilingual municipalities, Swedish speakers are in the majority, except in the regional capital Vaasa and Kaskinen. In 2010, Ostrobothnia had a total population of 177,946, of whom 45.2 per cent spoke Finnish as their native language. Half of the population (50.8 per cent) speak Swedish as their native language.

Kymenlaakso is a region in south-eastern Finland on the coast of the Gulf of Finland. The population of the region represents approximately 3.4 per cent of Finland's population, and the population density is 35.4 inhabitants per $\mathrm{km}^{2}$. There are 7 municipalities in Kymenlaakso. Three of them are cities. Kouvola (88,072 inhabitants) and Kotka $(54,824$ inhabitants) are the regional centres of Kymenlaakso. In 2010, Kymenlaakso had a population of 182,382 , of whom 95.3 per cent spoke Finnish as their native language.

Lapland is the largest $\left(92,661 \mathrm{~km}^{2}\right)$ and northernmost of the regions of Finland. Lapland is the home of about 3.6 per cent of the Finnish population, and is by far the least densely (2.0 inhabitants per $\mathrm{km}^{2}$ ) populated area in the country. Lapland includes 21 municipalities and the biggest towns in Lapland are Rovaniemi (the regional capital with 60,090 inhabitants), Kemi, and Tornio. In 2010, Lapland had a population of 183,488, of whom 97.3 per cent spoke Finnish as their native language.

North Karelia is a region in eastern Finland. The population of the region represents approximately 3.1 per cent of the Finnish population, and the population density is 9.3 inhabitants per $\mathrm{km}^{2}$, which is the third lowest figure in Finland. North Karelia includes 14 municipalities. Five of them are cities, and the regional capital Joensuu is by far the largest of them, with a population of 73,305 inhabitants. In 2010, North Karelia had a total population of 165,866, of whom 97.5 per cent spoke Finnish as their native language.

Pirkamaa is an inland region in Southern Finland. The total population of the region is the second largest in Finland. In 2010, the population of Pirkanmaa was 487,923 


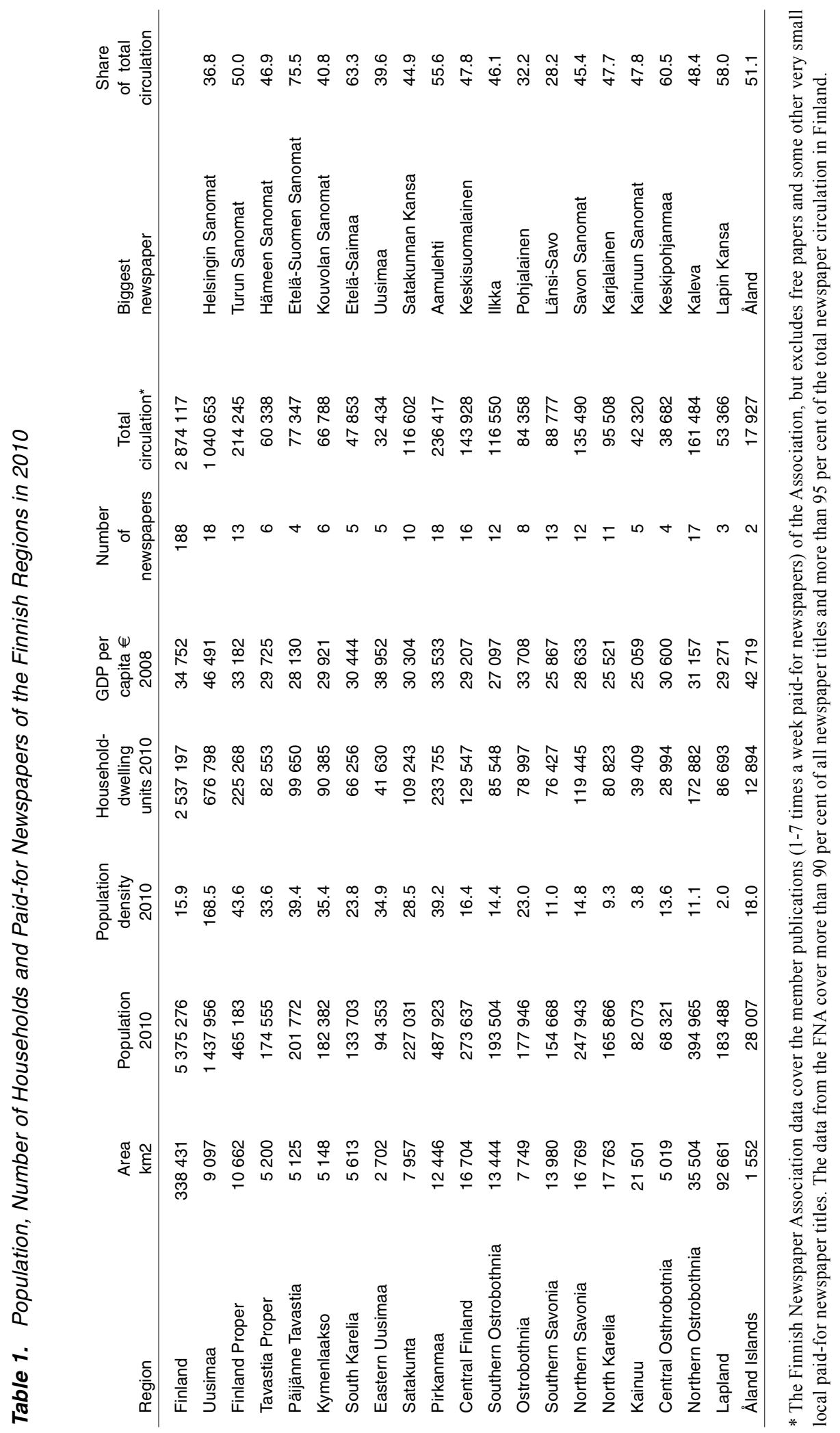


inhabitants. The population of the region represents 9.1 per cent of country's total population, and the population density is 39.2 inhabitants per $\mathrm{km}^{2}$. Pirkanmaa includes 22 municipalities, of which 11 have city status. Tampere, the regional centre and the third biggest city in Finland, is by far the largest city in the area (213,217 inhabitants). In 2010 approximately 96.4 per cent of inhabitants in the region spoke Finnish as their native language.

South Karelia is a region in south-eastern Finland. The population of the region represents approximately 2.5 per cent of Finland's population, and the population density is 23.8 inhabitants per $\mathrm{km}^{2}$. South Karelia includes 10 municipalities. Two of them are cities, and the regional capital Lappeenranta is by far the largest of them, with a population of 71,982 inhabitants. In 2010, South Karelia had a total population of 133,703, of whom 96.2 per cent spoke Finnish as their native language.

Southern Ostrobothnia is a region located on the west coast of Finland. The surface area of the region is the eight largest of the Finnish regions. In 2010, Southern Ostrobothnia's population was 193,504, making it the ninth most populous region in Finland. The population of the region represents 3.6 per cent of the country's total population, and the population density is 14.4 inhabitants per $\mathrm{km}^{2}$. There are 19 municipalities in Southern Ostrobothnia. Eight of them are cities, and Seinäjoki, the regional centre, is by far the largest city in the area (57,811 inhabitants). In 2010, approximately 98.5 per cent of inhabitants in the region spoke Finnish as their native language.

Tavastia Proper is a region in southern Finland. Tavastia Proper is the home of about 3.2 per cent of Finland's population, and the population density is 33.6 inhabitants per $\mathrm{km}^{2}$. The region includes 11 municipalities, and the biggest town is the regional capital Hämeenlinna (66,829 inhabitants). In 2010, Tavastia Proper had a total population of 174,555, of whom 97.4 per cent spoke Finnish as their native language.

Uusimaa is a region on the South coast of Finland. It borders the regions Finland Proper, Tavastia Proper, Päijänne Tavastia and Kymenlaakso. The Finnish capital Helsinki and the second largest city Espoo are both located centrally in Uusimaa, making it by far the most populous region in Finland. The population of the region represents approximately 26.8 per cent of the Finnish population, and the population density of 168.5 inhabitants per $\mathrm{km}^{2}$ is by far the highest. Until 2011, Uusimaa included $21 \mathrm{mu}-$ nicipalities. Eleven of them are cities and the biggest are Helsinki (588,549 inhabitants), Espoo (247,970 inhabitants) and Vantaa (200,055 inhabitants). In 2010, Uusimaa had a total population of $1,437,956$, of whom 83.3 per cent spoke Finnish as their native language, and 8.7 per cent spoke Swedish as their native language. Eight per cent of the population in Uusimaa have another foreign language as their native language.

In Figure 4, we have plotted the growth of market shares in the nine selected regions. In order to make the developments more comparable, the market share of the leading newspaper in each region in 1974 was given an index of 100 .

Figure 4 clearly shows the increase in the market shares of the leading newspaper, but the shape of the growth patterns varies quite substantially from a clear sigmoid to something of a stepwise growth pattern. These data will be analysed in the estimation stage.

One interesting question is to what extent these leading newspapers have managed to increase their household coverage. One could expect that a relatively strong growth of market shares would translate into an increasing household coverage. Figure 5 reveals that such an expectation is completely wrong. 
Tom Björkroth \& Mikko Grönlund The Growth of Leading Regional Newspapers

Figure 4. Index of Regionally Leading Newspapers' Market Shares (circulation) in Each Region (1974=100)

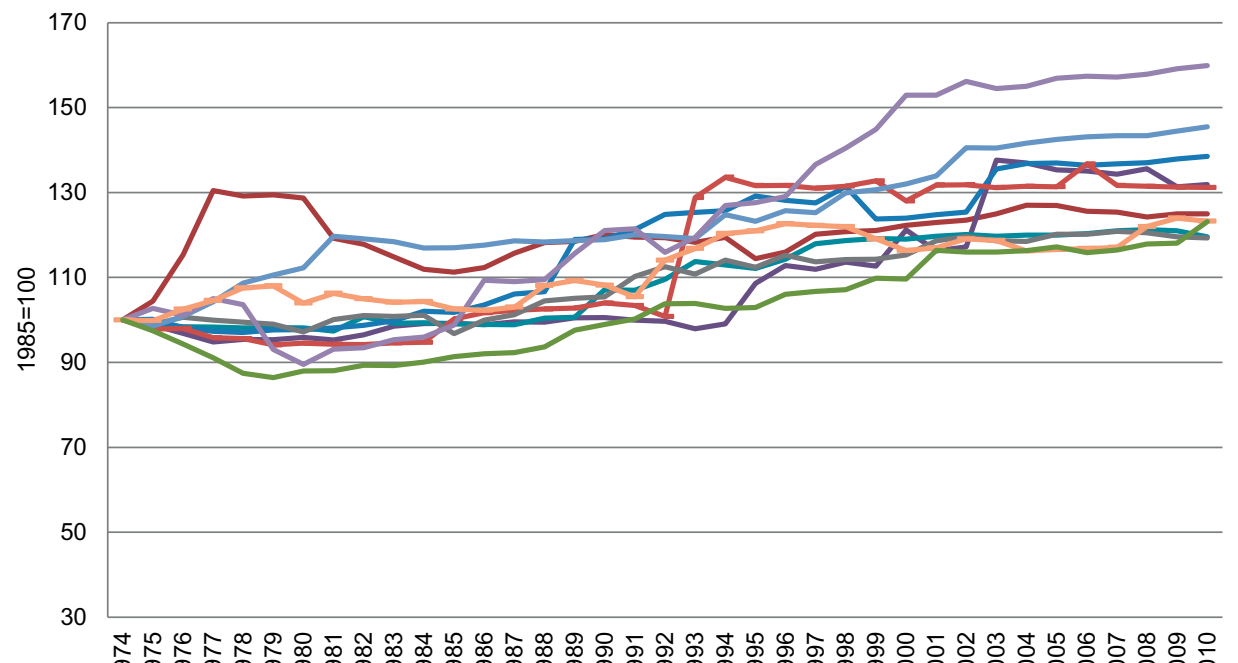

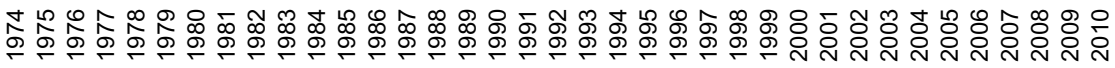

$\begin{array}{ll}\text { Eastern Uusimaa } & \text { Tavastia Proper } \\ \text { Kymenlaakso } & \text { South Karelia } \\ \text { Southern Osthrobotnia } & \text { Lapland } \\ \text { Northern Osthrobotnia } & \end{array}$

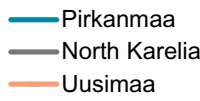

Figure 5. Index of the Leading Newspaper's Household Coverage in Each Region (1985=100)
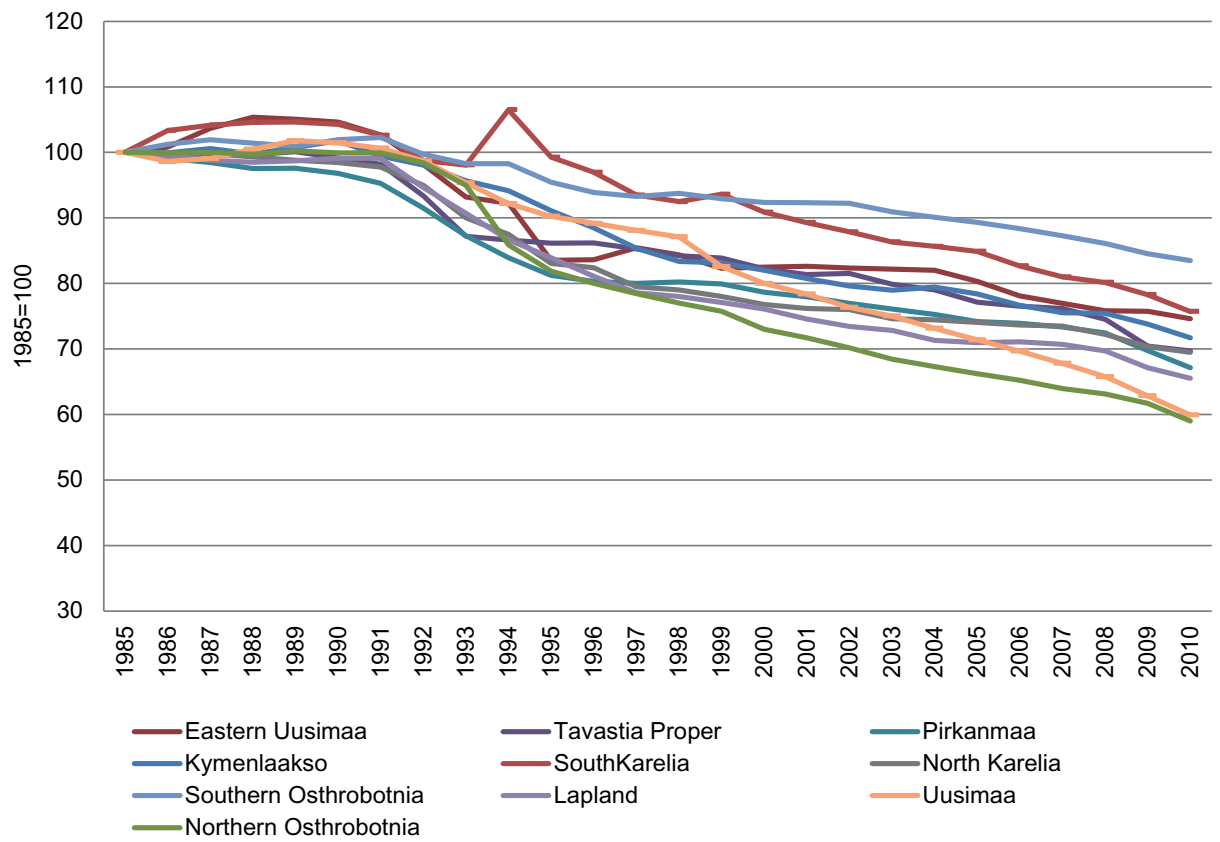
Studying the index $(1985=100)$ of development of household coverage for the leading newspapers between 1985 and 2010, it is clear that there has been a major change in all of these regions. One may argue that reasons for this development are found in the changing media consumption pattern, which in turn may have been affected by the technological development, but also by the dramatic economic depression in the early 1990s. Whatever the case may be, the developments call for an analysis of whether the household coverage of the leading newspapers is about to converge to some level and how these levels differ between each of the ten regions.

\section{Data and Estimation}

\section{Description of the Data}

In order to approximate the number of potential subscribers, we have used the number of household-dwelling units ${ }^{16}$ in the region. The total number of household-dwelling units in the region was calculated based on municipality level data from Statistics Finland. In this way, we may take into account the population growth and redistribution across regions.

We use annual data from each region on the circulation figures from 1974-2010. The circulation figures are based on data from the Finnish Audit Bureau of Circulations ${ }^{17}$. In order to make the most of the equation, (1) we relate the circulation figures of each paper ${ }^{18}$ to the total circulation. ${ }^{19}$ However, in order to highlight the distinction between the diffusion pattern of the market share and the role of the newspaper in the media consumption overall, we will relate the circulation figures to the number of potential subscribers, which is the number of households and firms in the region. We estimate Eq. (1) for the leading newspapers in 10 regions using the method of nonlinear least squares. In the table below, we show the estimates for the leading newspapers in nine regions, of which two, Eastern Uusimaa and Ostrobothnia, are the most prominently bilingual ${ }^{20}$ regions.

\section{Estimating Growth in Market Share and Household Coverage}

Estimation of Eq (1) added with an initial market share $\alpha_{0}$ :

$$
\widehat{m s}_{\mathrm{t}}=\alpha_{0}+\frac{1}{k+a b^{t}} \text {, where } b>0
$$

The level that the share of circulation converges to is then obtained by $\alpha_{0}+1 / k$.

The household coverage is estimated in a similar manner by assuming that it declines gradually to converge at some level lower than the initial level $\beta_{0}$. Hence, we estimate parameters $a, b$ and $k$ in the equation describing the decline in household coverage:

$$
\widehat{h h}_{\mathrm{t}}=\beta_{0}-\frac{1}{k+a b^{t}} \text {, where } b>0,0<k<1
$$

The level that household coverage converges to is then obtained by $\beta_{0}-1 / k$.

The parameter estimates in Table 2 show reasonably good t-values, and the model diagnostics were also otherwise encouraging. The estimates were sensitive to the starting values of the coefficients, as is typically the case in nonlinear estimation. Reasonable 
starting values were obtained by simulation in spread sheets. Table 2 gives a rather high estimate for $a$, which is a natural result owing to the added constant in the model. ${ }^{21}$ The estimations were performed using Shazam 10.0 software.

Table 2. Parameter Estimates of Logistic Growth Curves

\begin{tabular}{lcccccc} 
& \multicolumn{7}{c}{ Parameter estimates of logistic growth curve } \\
Region & $\mathbf{k}$ & $\begin{array}{c}\text { Market share } \\
\text { a }\end{array}$ & $\mathbf{b}$ & $\mathbf{k}$ & $\mathbf{a}$ & $\mathbf{b}$ \\
\hline Eastern Uusimaa (IU) & 2.6059 & 1.7092 & 0.36713 & 11.502 & 3500.0 & 0.59091 \\
& $(139.16)$ & $(2.22)$ & $(3.35)$ & $(20.078)$ & $(2972.3)$ & $(33.957)$ \\
Tavastia Proper (KH) & 7.9028 & $0.10 \mathrm{E}+07$ & 0.64195 & 7.3616 & 161.91 & 0.78920 \\
& $(21.53)$ & $(0.10 \mathrm{E}+07)$ & $(128.08)$ & $(25.017)$ & $(3.0920)$ & $(39.121)$ \\
Pirkanmaa (Pir) & 10.634 & $0.10 \mathrm{E}+06$ & 0.62792 & 4.3822 & 124.17 & 0.72212 \\
& $(46.78)$ & $(0.10 \mathrm{E}+06)$ & $(145.34)$ & $(23.512)$ & $(2.1401)$ & $(18.760)$ \\
Kymenlaakso (Kym) & 10.081 & $0.10 \mathrm{E}+07$ & 0.50 & 9.613 & 1200.0 & 0.688 \\
& $(31.96)$ & $(0.10 \mathrm{E}+07)$ & $(54.57)$ & $(37.106)$ & $(1199.6)$ & $(106.36)$ \\
South Karelia (EK) & 6.3386 & $0.10 \mathrm{E}+07$ & 0.53815 & 7.3099 & 4000.0 & 0.70064 \\
& $(29.07)$ & $(0.10 \mathrm{E}+07)$ & $(84.81)$ & $(10.840)$ & $(4000.0)$ & $(63.561)$ \\
Northern Karelia (PK) & 13.509 & 50000.0 & 0.64658 & 4.5728 & 500.00 & 0.64374 \\
& $(35.65)$ & $(49938.00)$ & $(98.56)$ & $(55.916)$ & $(499.28)$ & $(106.38)$ \\
Southern Osthrobothnia (EP) & 4.8066 & 44.889 & 0.91871 & 9.5810 & 3000.0 & 0.69014 \\
& $(4.85)$ & $(5.83)$ & $(69.64)$ & $(12.943)$ & $(2988.6)$ & $(49.230)$ \\
Lapland (Lap) & 4.8622 & 50000.0 & 0.65350 & 5.8070 & 599.99 & 0.66337 \\
& $(24.77)$ & $(49999.00)$ & $(89.70)$ & $(46.331)$ & $(429.21)$ & $(99.699)$ \\
Uusimaa (Uu) & 16.850 & 50000.0 & 0.62428 & 3.105 & 2000.00 & 0.65450 \\
Northern Ostrobothnia (PPoh) & 12.313 & 50000.0 & 0.724 & 3.59 & 500.0 & 0.67 \\
& $(7.40)$ & $(50000.00)$ & $(55.14)$ & $(-36.55)$ & $(-435.66)$ & $(88.89)$ \\
\hline
\end{tabular}

\section{Implications of the Estimation Results of Circulation Growth in Relation to Potential Audience}

We may use the estimation results above to derive the levels of market share and household level coverage. In order to do this for the market share, we will use the estimate of the parameter $k\left(k^{*}\right)$ and its value on the lower bounds of the 90 and $95 \%$ confidence intervals $\mathrm{k}_{\mathrm{L}} \cdot{ }^{22}$ As a result, we will get an estimate of the convergence level of the market share $\left(S^{*}\right)$ for the leading newspaper in each region together with an estimate of the upper level of this estimate (S-upper) based on $k_{L}$.

From Table 3 we can infer that, in many of the regions, the leading newspapers have achieved, by 2010, the level of convergence implied by the estimate of $k^{*}$ for each region. In a few cases the models allow us to expect a growth of a few percentage points (Tavastia Proper and South Karelia). Southern Ostrobothnia seems to be an exception to the estimate, and the lower level of $k$ suggests an increase in the market share between 6.2 and 9 per cent respectively from the level of year 2010 .

It is important to note that the model and parameter estimates used do not seem to suggest that any of the leading regions mentioned is characterized by a strictly increasing market share. One can instead conclude that the market shares tend to converge to shares of circulation between one extreme of around 36 per cent to the other extreme of 65 per cent. At the newspaper level, this means that the fringe $d$, left to competi- 
tor newspapers, is quite large, from 35 per cent to 64 per cent of the total circulation, depending on the region. This does not support a finding of such a virtuous circle for any of the leading newspapers that would completely exhaust or pre-empt the fringe for competing newspapers. However, this conclusion refers only to the situation at the newspaper level, because from these results we cannot state anything definite about the development from the point of view of ownership.

Table 3. Actual Market Shares of Leading Newspapers in Different Regions together with Estimated Convergence Levels

\begin{tabular}{lcccccccccc} 
& IU & PK & Pir & Lap & Uu & KH & Kym & EK & EP & PPoh \\
\hline Ms1974 & 0.317 & 0.400 & 0.465 & 0.363 & 0.299 & 0.355 & 0.295 & 0.482 & 0.317 & 0.393 \\
Ms2010 & 0.396 & 0.477 & 0.556 & 0.580 & 0.368 & 0.469 & 0.408 & 0.633 & 0.461 & 0.484 \\
$\boldsymbol{k}^{*}$ & 2.606 & 13.509 & 10.634 & 4.862 & 16.85 & 7.903 & 10.801 & 6.339 & 4.807 & 12.313 \\
$\boldsymbol{k}_{\mathbf{L}}$ & & 12.870 & 10.250 & 4.532 & 15.60 & 7.285 & 10.12 & 5.971 & 3.139 & 9.512 \\
$\hat{S}^{*}$ & 0.701 & 0.474 & 0.559 & 0.568 & 0.358 & 0.482 & 0.388 & 0.640 & 0.525 & 0.474 \\
$\hat{S}_{\text {-upper }}$ & & 0.478 & 0.563 & 0.583 & 0.363 & 0.493 & 0.394 & 0.650 & 0.636 & 0.498 \\
\hline
\end{tabular}

Regarding household coverage, we can observe from the calculations in Table 4 that, in many of the regions, the level of household coverage in 2010 was lower than predicted by estimations of the level of convergence. This implies that the fringe d' of Figure 2 (Panel II) is substantial and increasing, but varies quite substantially between the regions.

Table 4. Actual Household Coverage of Leading Newspapers in Different Regions together with Estimated Convergence Levels

\begin{tabular}{lcccccccccc} 
& IU & PK & Pir & Lap & UU & KH & Kym & EK & EP & PPoh \\
\hline$h h 1985$ & 0.414 & 0.812 & 0.838 & 0.575 & 0.945 & 0.492 & 0.421 & 0.604 & 0.753 & 0.767 \\
$h h 2010$ & 0.309 & 0.564 & 0.563 & 0.377 & 0.566 & 0.343 & 0.302 & 0.457 & 0.629 & 0.452 \\
$k^{*}$ & 11.502 & 4.573 & 4.382 & 5.807 & 3.105 & 7.362 & 9.613 & 7.310 & 9.581 & 3.59 \\
$k_{\text {90L }}$ & 10.520 & 4.433 & 4.064 & 5.593 & 2.897 & 6.860 & 9.171 & 6.159 & 8.318 & 3.389 \\
$k_{\text {95L }}$ & 10.320 & 4.405 & 3.999 & 5.549 & 2.854 & 6.757 & 9.08 & 5.923 & 8.059 & 3.342 \\
$h_{\text {-est }}^{*}$ & 0.327 & 0.593 & 0.610 & 0.403 & 0.623 & 0.356 & 0.317 & 0.467 & 0.648 & 0.488 \\
$h_{\text {Low90 }}$ & 0.319 & 0.586 & 0.592 & 0.397 & 0.600 & 0.346 & 0.312 & 0.441 & 0.632 & 0.472 \\
$h_{\text {Low95 }}$ & 0.317 & 0.585 & 0.588 & 0.395 & 0.585 & 0.344 & 0.311 & 0.435 & 0.629 & 0.468 \\
\hline
\end{tabular}

There are however, exceptions, such as Northern Karelia (PK) and Southern Karelia (EK), where the household coverage in 2010 was still above the estimated level of convergence.

We may of course discuss what underlies this development and why the estimated levels of convergence do not correspond to the levels observed in 2010. It is possible that we are again about to experience a significant shift in media consumption habits. And again we may have to identify several underlying reasons. The technological development has now, perhaps much more strongly than in the early 1990s, contributed to the change in media consumption habits. Economic downturns may have influenced this as well, but presumably to a smaller extent than in the 1990s. The future of household coverage may be even more challenging now, as the value added tax is added to the 
newspaper subscriptions. In the presence of viable alternatives for media consumption, price sensitiveness in relation to newspaper subscription may be greater than in the past. These hypotheses and questions are, however, best answered by empirical studies.

\section{Shares of Circulation in Bilingual Regions}

Regarding the bilingual regions, we have provided the estimation results and the level of convergence of Eastern Uusimaa (IU), where the development of the market share of the leading Finnish newspaper can be described with a logistic growth function, which is not the case in the region of Ostrobothnia. In Ostrobothnia, the market share of the leading newspaper (Pohjalainen) has decreased by ten per cent between 1974 and 2010, which was why this region was not considered in the estimations above. The decrease shows a clear logistic pattern with some uncertainty regarding the level of convergence. However, there is an interesting finding regarding the second largest Swedish newspaper (Vasabladet). Its positive market share growth shows a sigmoid pattern with a clear level of convergence in the 25 to 30 per cent interval, with the typical "dip" in the period 2009-2010.

Figure 6. Development of Circulation Shares of the two Biggest Newspapers in Selected Bilingual Regions

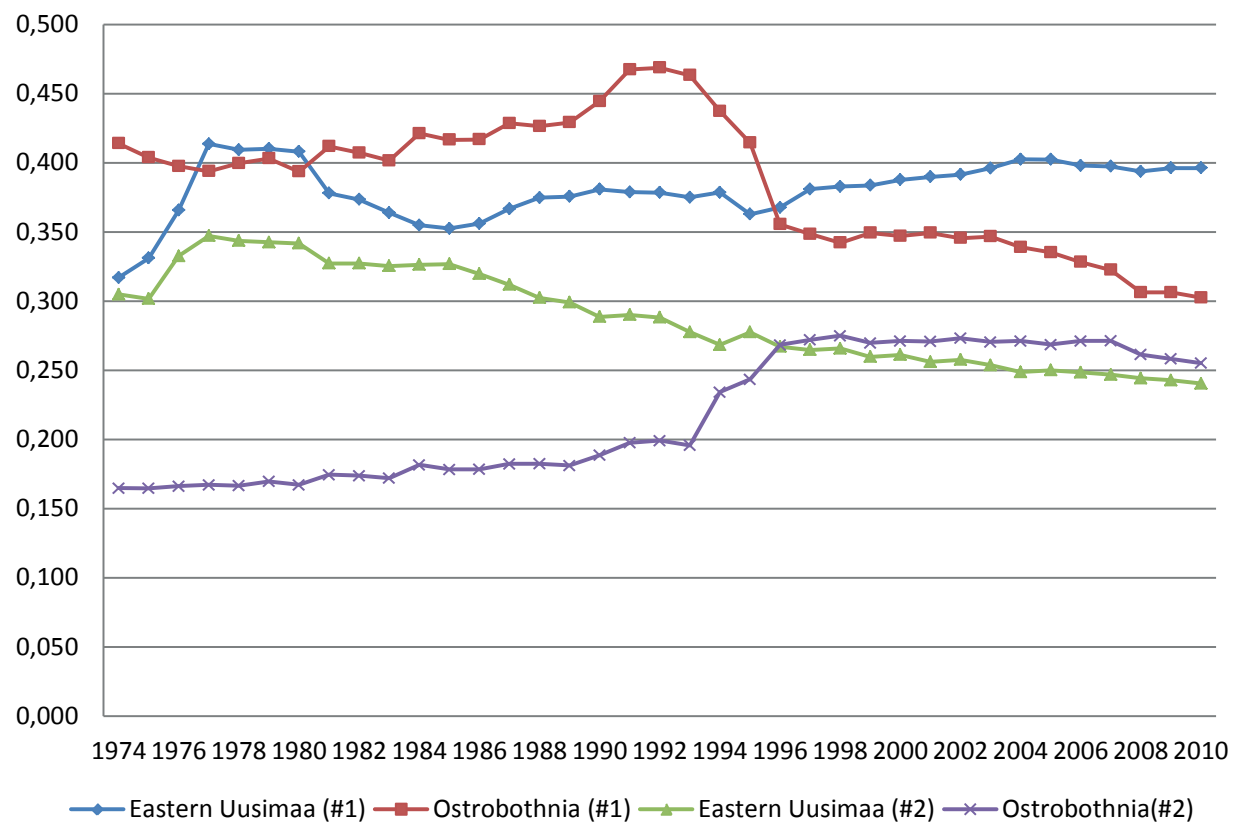

Bilingual regions seem to differ from each other both regarding the development of the "market share" of the leading Finnish newspaper, but especially regarding the second largest Swedish newspaper. In Eastern Uusimaa, the development can perhaps be explained by the proximity of the Uusimaa and Helsinki regions. The readers in Eastern Uusimaa may consider the Finnish Helsingin Sanomat and the Swedish Hufvudstadsbladet as substitutes for their own regional newspapers, while the existence of such substitutes is less clear in Ostrobothnia, at least regarding the Swedish Vasabladet. 
The Swedish newspapers have a moderate share of the total circulation in their regions. However, these newspapers indicate that their target group consists of Swedish-speaking and bilingual households, and according to the "Media card" for these newspapers, the household coverage varies in the interval between 51 and 100 per cent depending on the municipality being considered. This feature has been explained by the early establishment of Swedish newspapers in Finland, the regional focus of newspapers and by the slowly changing reading habits, despite the increasing popularity of alternative media (Gustafsson 2002; Nordqvist, 2002).

\section{Conclusions}

In this article, we chose to study the market shares of the leading regional newspaper in the regions where these shares have increased between 1974 and 2010. Our estimation results show that the shape and pace of the growth patterns vary substantially between the regions. The levels of convergence of the growing market shares of the leading newspapers also vary between the regions, leaving, however, a substantial fringe for competing newspapers. On one hand, these regional differences can be seen to reflect the state of competition between newspapers, on the other, there are geographical and demographical factors behind these differences: Having more than one regional centre or a relatively large Swedish-speaking population may explain some of these differences.

Moreover, one of our main findings was that no region was described by a strictly increasing share of circulation of the leading newspaper. With the highest level of convergence reaching about 65 per cent, there is substantial scope for the survival of competing newspapers in the future.

However, the growth of market shares of the leading regional newspapers does not reveal the whole picture of competitive interaction in these markets. According to Statistics Finland, the average size of a household-dwelling unit has decreased from 2.56 to $2.07^{23}$ between 1985 and 2010 . At the same time, the total number of household-dwelling units has increased from $1,887,710$ to $2,537,197$. Because of the declining circulations and increasing number of households, the household coverage of the leading regional newspaper in many regions has been declining significantly. One of the outcomes of our study was that, in many of the regions, the level of household coverage in 2010 was lower than predicted by estimations of the level of convergence. The development has not been identical around the country, and there are prominent differences in levels between regions.

Having briefly studied the bilingual regions, we found them to differ from each other both regarding the development of the "market share" of the leading Finnish newspaper and especially regarding the Swedish, second largest newspaper. Interestingly, the share of circulation of the Swedish language newspaper followed a growing sigmoid pattern. However, even in these regions, we observed a continuous decline in the household coverage of the Swedish language newspapers as well.

Our findings imply that media consumption patterns are important and that newspapers face increasing pressure from inter-media competition. What underlies this development, and why do the estimated levels of convergence not correspond to the levels observed in 2010? It is possible that we are facing a significant shift in media consumption habits that has several under-lying causes. The technological development 
has contributed more, than it did in the early 1990s, to the change in media consumption habits. Economic downturns may also have influenced this as well, but presumably to a smaller extent than in the 1990s. The future of the development of household coverage may be even more challenging, as the value added tax was added to newspapers subscriptions in 2012. In the presence of viable alternatives for media consumption, price sensitiveness in newspaper subscription may be greater than in the past.

\section{Notes}

1 Dr Tom Björkroth works as Senior Adviser at The Finnish Competition and Consumer Authority. Mikko Grönlund is Research Manager of Brahea Centre at University of Turku, Finland. We gratefully acknowledge the comments and improvements suggested by an anonymous reviewer and by our former colleague Mrs Irma Vento-Vierikko. We also gratefully acknowledge the financial support received from The Society of Swedish Literature in Finland (Lars och Ernst Krogius forskningsfond). The views expressed in this article are our personal ones and do not necessarily represent the opinions of our employer or any other authority. All errors and inaccuracies are ours.

2. Melnik, Shy \& Stenbacka (2008) show, in a theoretical model, how dominance can depend on the difference in market shares between the largest and second largest firm and on the importance of barriers to market entry.

3. Horwitz (2004, 18-19), for example, has argued that antitrust theory that focuses solely on market power over pricing will be too limited, because it may overlook other negative features of media concentration. Such features include "diminished editorial voice, the decline of journalistic values, diminution of the press's watchdog function, and reduction in the diversity of ideas, and, as a consequence, thwarts democratic deliberation".

4. The word "dominant" refers to the newspaper having the largest market share in terms of circulation, and not necessarily to dominance in the context of Competition Law.

5. However, the time lag before the majority newspaper starts to grow aggressively may be quite long, which increases the lifetime of the smaller newspaper. The value of $\beta$ is in fact subject to quite interesting interactions. The number of advertisers is not necessarily exogenous, but could depend positively on the degree of ad-lovership, i.e. $A=f(s)$.

6. These points were mentioned by Furhoff (1973), but may of course include other aspects as well.

7. It is possible that the data segment is too short to show a convergence towards a certain level. According to Pindyck \& Rubinfeld (1991), a diffusion equation that is linear in parameters and which can be estimated as an approximation of Equation (1) is $\Delta y y_{t}=c_{1}-c_{2} y_{t-1}$, where parameters describing a quadratic growth (or decline) of circulation should be less than unity and usually be within the range of .05 to .50 .

8. Newspapers include all paid-for papers published 1-7 times a week.

9. Their approach relied on the finding of Lacy \& Martin (2004) that the relief in inter-media competitive pressure is captured by an increase in the newspaper's share of total advertising revenues, and that intensified intra-media competition is reflected in the increase in the ratio of advertising revenues to circulation revenues. The latter was originally proposed by Kind, Nilssen \& Sørgard (2005).

10. On the effects and measurement of cross ownership, see, e.g., O’Brien, D. P., \& Salop, S. C. (2000) or Campos \& Vega (2002).

11. This may seem a trivial and unnecessary point in the case of media markets, because one may assume that consumers constantly increase the time devoted to different media. However, in analysing the unilateral effects of mergers, such as Upward Pricing Pressure (UPP), the share of consumers that leave the market may be decisive for the assessment. See, e.g., Shapiro (1996) p. 25.

12. In November 2011, the Finnish Parliament voted to increase the VAT rate on newspaper and magazine subscriptions from the zero VAT rate to the reduced VAT rate of 9 per cent. The new 9 per cent VAT rate came into effect on 1 January 2012.

13. Finland is divided into 19 regions (Finnish: maakunta), which belong to the NUTS 3 level in the regional classification system of the European Union (NUTS). The regions are governed by regional councils, which serve as forums of cooperation for the municipalities of a region. The main tasks of the regions are regional planning and development of enterprise and education. Until the beginning of 2011, Finland was divided into 20 regions. The Government of Finland decided on the abolition of Eastern Uusimaa in 2009 and all the municipalities of Eastern Uusimaa joined the region of Uusimaa in the beginning of 2011. Because the last year in our study is 2010, we have processed Eastern Uusimaa separately. The 20 regions referred to in this study are thus: Uusimaa (Uusimaa), Itä-Uusimaa (Eastern Uusimaa), Varsinais- 
Suomi (Finland Proper), Kanta-Häme (Tavastia Proper), Päijät-Häme (Päijänne Tavastia), Kymenlaakso (Kymenlaakso), Etelä-Karjala (South Karelia), Satakunta (Satakunta), Pirkanmaa (Pirkanmaa), KeskiSuomi (Central Finland), Etelä-Pohjanmaa (Southern Ostrobothnia), Pohjanmaa (Ostrobothnia), EteläSavo (Southern Savonia), Pohjois-Savo (Northern Savonia), Pohjois-Karjala (North Karelia), Kainuu (Kainuu), Keski-Pohjanmaa (Central Osthrobotnia), Pohjois-Pohjanmaa (Northern Ostrobothnia), Lappi (Lapland) and Ahvenanmaa (Åland Islands).

14. A detailed description is found in Grönlund \& Björkroth (2011)

15. This is consistent with the shipment test, or the Elzinga-Hogarty test, used in antitrust analysis. The idea is that a relevant geographical market is well defined if there is "little in from outside" and "little out from inside".

16. Household-dwelling unit is defined according to the official definition provided by the Statistics Finland.

17. Additional data were collected during the Media Economics, Content, and Diversity Project funded by the Academy of Finland.

18. In Finland, all regional number one newspapers, measured by circulation, are 7-day-a-week newspapers. The only exception is 6-day-a-week newspaper, Åland, on the Åland Islands. There are only two paid-for newspapers on the Åland Islands, and neither of them is published 7 days a week.

19. By doing this we will get an interpretation of coefficient $k$ as being the inverse of the share that the newspaper's market share is converging to. I.e., if $k$ equals 2 , the newspaper's share converges to 50 per cent. Total circulation figures for each region include circulation figures of all paid-for newspapers (1-7 days a week) in that region.

20. The share of the Swedish-speaking population in Eastern Uusimaa is 31.7 per cent and in Ostrobothnia 50.8 per cent.

21. In practice, the addition of a constant to the model puts the intercept of the logistic function close to zero. With a traditional logistic function of the form $y_{t}=N /\left(1+a b^{-t}\right)$, the intercept of the model would be $N /$ $(1+a)$. In our case, this explains the large estimate of $a$.

22. Having plotted the simultaneous confidence intervals of parameters $k$ and $b$, it is evident that for some values of $k$ the estimate of $b$ is not within the 95 per cent confidence interval. However, this does not alter the interpretation of $k$ as being the inverse of the level to which the market share of the leading newspaper is converging to.

23. A household-dwelling unit consists of the permanent occupants of a dwelling.

\section{References}

Björkroth, T. \& Grönlund, M. (2012) 'The growth of leading regional newspapers-evidence on circulation spirals and scope for competition', Paper presented at the XXI World Media Economics Conference in Thessaloniki. 24-5.2012.

Campos, J. \& Vega, G. (2002) 'Concentration measurement under cross-ownership. The case of Spanish electricity sector’, Documento de Trabajo 2002-06. Universidad de Las Palmas

Furhoff, L. (1973) 'Some reflections on newspaper concentration', The Scandinavian Economic History Review, 21 (1): 1-27.

Gabszewicz, J.J., Garella, G.P. \& Sonnac, N. (2007) 'Newspapers' market shares and the theory of the circulation spiral', Information Economics and Policy 19 (3-4): 405-413.

Grönlund, M. \& Björkroth, T. (2011) 'Newspaper Market Concentration, Competitive Pressure and Financial Performance: The Case of Finland', Journal of Media Business Studies 8 (3): 19-52.

Gustafsson, K.E. (2002): Finlandssvenska medier i jämförande perspektiv. Kap 7 i Moring, T. \& Nordqvist, A. (red) Svenska medier $i$ Finland. Helsingfors

Gustafsson, K.E. (1978) 'The Circulation Spiral and the Principle of Household Coverage', Scandinavian Economic History Review 26 (1): 1-14.

Horwitz, R.B. (2004) On Media Concentration and the Diversity Question. Mimeo. Department of Communication, University of California.

Jyrkiäinen, J. \& Savisaari, E. (2003) Sanomalehdistön nykytila. In Nordenstreng,

Kaarle; Wiio, Osmo A. (eds.) Suomen Mediamaisema. WSOY, Helsinki.

Kind, H.J., Nilssen, T. \& Sørgard, L. (2005) 'Financing of media firms- Does competition matter?' Mimeo. Norwegian School of Economics and Business Adminstration. Retrieved from: http:/www.econ.au.dk/ vip_htm/povergaard/pbohome/Workshop_Oct_2005_files/Nilssen_Financing_Of_Media_Firms.pdf.

Lacy, S. \& Martin, H.J. (2004) 'Competition circulation and advertising', Newspaper Research Journal 25(1): 18-39.

Melnik, A., Shy, O. \& Stenbacka, R. (2008) 'Assessing Market Dominance', Journal of Economic Behavior \& Organization 68 (1): 63-72. 
Nordqvist, A. (2002): Tvåspråkiga finlandssvenskars tidningsläsning. Kap 7 i Moring, T. \& Nordqvist, A. (red) Svenska medier $i$ Finland. Helsingfors.

O’Brien, D.P. \& Salop, S.C. (2000) 'Competitive effects of partial ownership: Financial interest and corporate control', Antitrust Law Journal 67 (3): 559-614.

Picard, R. \& Grönlund, M. (2003) A 50Year Business History of the Finnish Newspaper Industry. A research paper presented at the 15th Nordic Conference of Media and Communication Research, Kristiansand, Norway, August 15-17, 2003.

Picard, R. (2002) Competition in Media Markets. Chapter 7 in Picard, R. The Economics and Financing of Media Companies. Fordham University Press. New York

Picard, R.G. (1988). Measures of concentration in the daily newspaper industry. Journal of Media Economics 1, 61-74.

Pindyck, R.S. \& Rubinfeld, D.L. (1991) Econometric Models \& Economic Forecasts. McGraw-Hill.

Shapiro, C. (1996) 'Mergers with differentiated products', Antitrust, Spring: 23-30.

TOM BJÖRKROTH, Dr., Senior Adviser, Finnish Competition and Consumer Authority, Helsinki, tom.bjorkroth@kkv.fi

MIKKO GRÖNLUND, M.Sc. (Econ. \& Bus.Adm.), Research Manager, Brahe Centre, University of Turku, mikko.s.gronlund@utu.fi 